\title{
Pharmacological Potentials, Characterization and Fatty Acids Profile of Persea americana Mill. (Avocardo) Seed Oil Using Gas Chromatography- Mass Spectroscopy
}

\author{
Omeje $\mathrm{KO}^{1 *}$, Ozioko $\mathrm{JN}^{2}$ and Opmeje $\mathrm{HC}^{3}$ \\ ${ }^{1}$ Department of Biochemistry, University of Nigeria, Nsukka, Enugu State, Nigeria \\ ${ }^{2}$ Department of Science Laboratory Technology, University of Nigeria, Nsukka, Enugu State, Nigeria \\ ${ }^{3}$ Department of Biochemistry, University of Port Harcourt, Choba, Rivers State, Nigeria
}

\begin{abstract}
In this study, Avocado seed oil was extracted using sohxlet apparatus, n-hexane: chloroform $(30: 70)$ at $70^{\circ} \mathrm{C}$ for 3 $\mathrm{h}$, characterized and the pharmacological potentials assessed. The percentage oil yield was $36.93 \%$, brown in colour and remained liquid at room temperature. The acid, peroxide and iodine values were $7.86 \mathrm{mg} / \mathrm{KOH} / \mathrm{g}, 42.11 \mathrm{meq} /$ $\mathrm{Kg}^{-1}$ and $33.21 \mathrm{mg} / 100 \mathrm{~g}$ respectively. The identified fatty acids included Dodecanoic acid (1.05\%), tetradecanoic acid $(0.86 \%)$, n-hexadecanoic acid $(13.19 \%)$, hexadecanoic acid $(4.12 \%), 9,12$-octadecanoic acid $(0.28 \%)$, 11-octadecanoic acid $(0.45 \%)$, oleic acid $(40.33 \%)$, n-hexadecanoic acid $(9.69 \%), 1, E-11-Z-13-o c t a d e c a t r i e n e ~(11.45 \%), 1, E-11-Z-13-$ octadecatriene $(6.78 \%)$, undecylanic acid $(6.31 \%)$, palmitaldehyde diisopentylacetal $(1.14 \%)$, 9-octadecanal $(1.18 \%)$ and $(E)-13$-docosenoic acid $(3.17 \%)$. The presence of fatty acids such as undecylenic acid, oleic acid and other essential fatty acids suggests the seed oil could possess important pharmacological properties.
\end{abstract}

Keywords: Seed oil; Fatty acid profile; GC-MS; Pharmacological potential; Agro waste

\section{Introduction}

Persea americana Mill. (Avocado) is a tree plant, native to Central America, cultivated in tropical and subtropical climates around the world, belonging to the family Lauraceae, used in traditional medicine for the treatment of various ailments, such as monorrhagia, hypertension, stomach ache, bronchitis, diarrhea, and diabetes [1]. Fluid extract of the avocado leaves is widely used in pharmaceutical products, mainly due to the diuretic characteristic of the present compounds in plant leaves [2].

Peptone, $\beta$-galactoside, glycosylated abscisic acid, alkaloids, cellulose, polygalacto urease, polyuronoids, cytochrome $P-450$, and volatile oils are reported to be present in this plant [1]. The fruit is a berry, consisting of a single large seed, surrounded by a butter pulp.

It contains different oil levels in the pulp, thus it is widely used in pharmaceutical and cosmetic industries, and for obtaining commercial oils similar to olive oil, because of their similar fatty acid composition [2]. The consumption of avocado fruit leads to the production of agro waste which includes the non-edible pulp and seed. Hence, the need to assess the pharmacological potentials of the seed oil of avocado.

The importance of oil span from energy generation, through membrane formation and maintenance to the biosynthesis of other essential compounds in the body. Hamm, et al. [3] reported the presence of organic molecules, which are mainly triacylglycerols, diacylglycerols, monoacylglycerols, free fatty acids and other minor components such as phospholipids, phytosterols, tocopherols and tocotrienols and hydrocarbons in oil. Seeds of plants have been used since antiquity as sources of vegetable oil [4]. Some main oil seeds as enumerated by Ononogbu [5] include coconut, soybeans, cottonseeds and ground nut. There are challenges facing the use of these seeds for oil production since there form part of the staple foods. Hence, the need to evaluate the agro waste (Avocado seed) as an alternative source of oil.

\section{Materials and Methods}

Gas Chromatography-Mass Spectroscopy (GCMS-QP2010 plus
Shimadzu, Japan), n-hexane and other chemicals were products of Sigma-Aldrich, USA.

\section{Plant sample collection and preparation}

Seed of Persea americana Mill. (Avocado) was picked from its natural habitat in Edem-ani community of Nsukka LGA, Enugu state, Nigeria. The seed was sliced and sun dried for one fourteen days. The dried seed was ground using electric blender.

\section{Extraction of seed oil using soxhlet apparatus}

Milled sample weighing $34.48 \mathrm{~g}$ was placed in a thimble before adding the solvent (hexane: chloroform) in a ratio $30: 70 \mathrm{ml}$ in the flat bottom flask. The set-up was heated at $70^{\circ} \mathrm{C}$ for $3 \mathrm{~h}$. After the extraction processes, the filtrate was exposed to the atmosphere and the residual solvent evaporated and oil extracted was quantified.

\section{Gas chromatography-mass spectrometry analysis}

Gas Chromatography-Mass Spectroscopy (GC-MS) analysis was carried out on a GC system comprising a Gas Chromatograph interfaced to a Mass Spectrometer (Schimadzu GCMS-QP2010), employing the following conditions: Column Elite-1 fused silica capillary column $(30 \times 0.25 \mathrm{~mm}$ ID $\times 1 \mathrm{EM} \mathrm{df}$, composed of $100 \%$ Dimethyl poly siloxane), operating in electron impact mode at $70 \mathrm{eV}$; helium (99.999\%) as carrier gas at a constant flow of $1 \mathrm{ml} /$ minute and a sample injection volume of $1 \mu \mathrm{l}$ which was employed (split ratio of

*Corresponding author: Omeje KO, Department of Biochemistry, University of Nigeria, Nsukka, Enugu State, Nigeria, Tel: 07030436813; E-mail: Kingsley.omeje@unn.edu.ng

Received: August 22, 2018; Accepted: August 29, 2018; Published September 05, 2018

Citation: Omeje KO, Ozioko JN, Opmeje HC (2018) Pharmacological Potentials Characterization and Fatty Acids Profile of Persea americana Mill. (Avocardo) Seed Oil Using Gas Chromatography-Mass Spectroscopy. Biochem Anal Biochem 7: 361. doi: 10.4172/2161-1009.1000361

Copyright: (c) 2018 Omeje KO, et al. This is an open-access article distributed under the terms of the Creative Commons Attribution License, which permits unrestricted use, distribution, and reproduction in any medium, provided the original author and source are credited. 
10:1) injector temperature $250^{\circ} \mathrm{C}$; ion-source temperature $280^{\circ} \mathrm{C}$. The oven temperature was programmed from $110^{\circ} \mathrm{C}$ (isothermal for 2 minutes), with an increase of $10^{\circ} \mathrm{C} /$ minute, to $200^{\circ} \mathrm{C}$, then $5^{\circ} \mathrm{C} /$ minute to $280^{\circ} \mathrm{C}$, ending with a 9 minutes isothermal at $280^{\circ} \mathrm{C}$.

\section{Results and Discussion}

Oil was extracted using $\mathrm{n}$-hexane and chloroform in the ratio 30:70. The percentage oil yield from the seed of African star cherry was 36. 93\%. Characteristics of avocado seed oil are shown in Table 1. The oil was liquid at room temperature. Acid peroxide and iodine value of the oil was $7.86 \mathrm{mg} / \mathrm{KOH} / \mathrm{g}, 42.11 \mathrm{meq} / \mathrm{Kg}-1$ and 33.21 $\mathrm{mg} / 100 \mathrm{~g}$ respectively. The percentage oil yield of avocado seed was high when compared to the study (B. parkii, $34.0 \%$, S. setegera $33.0 \%$, D. microcarpum, $7.42 \%$ ) of Kyari [6]. The seed oil yield of L. lanceolata (40.0\%), and S. birrea (42\%) [6] were higher than $36.93 \%$ obtained for Avocado seed. Also, African star fruit seed yielded $10.71 \%$ of oil [4] (2012), which is lower than the oil yield of this study.

Acid value is the measure of percentage content of free fatty acids in a substance, and degree of rancidity [5], which determines the freshness of the oil. The acid value $(7.86 \mathrm{mg} / \mathrm{KOH} / \mathrm{g})$ of Avocado seed oil is high when compared to the value of reported by Adepoju, et al. [7]. Acid values less than $1 \%$ were reported by Kyari [6]. This result shows low content of free fatty acid which may reuslt to low lipolytic activities.

Peroxide value is an index of rancidity [4]. Peroxide value of 42.11 $\mathrm{meq} / \mathrm{Kg}^{-1}$ was obtained for Avocado seed oil. The PV was low when compared to report of Kyari [6] on six oil seeds, high PV of 77.5, 95.0, $150.0,135.0$ were obtained for B. parkii, L. lanceolata, D. microcarpum and B. sapida.

Iodine value (IV) is the number of grams of iodine that combines

\begin{tabular}{|c|c|}
\hline Parameter & Property \\
\hline Colour & Brown \\
\hline State at room temp. & Liquid \\
\hline Acid value & $7.86 \mathrm{mg} / \mathrm{KOH} / \mathrm{g}$ \\
\hline Peroxide value & $42.11 \mathrm{meq} / \mathrm{kg}^{-1}$ \\
\hline lodine value & $33.21 \mathrm{mg} / 100 \mathrm{~g}$ \\
\hline
\end{tabular}

Table 1: Characterization table for Avocado seed oil. with $100 \mathrm{~g}$ of lipids, which shows the degree of unsaturation of the fat or oil, the oil is classified as a non-drying oil, and since its iodine value is less than 100 [5]. Iodine value of $33.21 \mathrm{~g} / 100 \mathrm{~g}$ was obtained in this study. This value is low when compared to $35 \mathrm{mg} / 100 \mathrm{~g}$ obtained by Adebayo et al. [4] and the six values obtained by Kyari [6], soursop seed oil [7].

Gas Chromatography-Mass Spectroscopy (GCMS-QP2010 plus Shimadzu, Japan), system is a very efficient technique commonly used for the identification and quantification of fatty acids in substances. The unknown organic compounds in the complex mixture found in the seed oil were matched with the National Institute of Standards and Technology (NIST) library. Gas Chromatography-Mass Spectrometry analysis (GC-MS) has been reported as an important tool for the identification and quantification of fatty acids [8].

Fourteen peaks were observed from the spectra of the study for the oil extracted from the seed of Avocado as shown in Figure 1. The compounds were confirmed by their retention time, percentage area, molecular weight and formulae respectively. Dodecanoic acid (1.05\%), tetradecanoic acid $(0.86 \%)$, n-hexadecanoic acid $(13.19 \%)$, hexadecanoic acid (4.12\%), 9,12-octadecanoic acid (0.28\%), 11-octadecanoic acid $(0.45 \%)$, oleic acid $(40.33 \%)$, n-hexadecanoic acid (9.69\%), 1,E-11-Z-13-octadecatriene (11.45\%), 1,E-11-Z-13octadecatriene (6.78\%), undecylanic acid (6.31\%), palmitaldehyde diisopentylacetal (1.14\%), 9-octadecanal (1.18\%) and (E)-13docosenoic acid (3.17\%) were identified in the seed oil of Avocardo. $87.75 \%$ of the seed oil was observed to be essential fatty acid with oleic acid contributing $40.33 \%$ (Table 2 and Figure 2).

Oleic acid has been reported to improve immune system by interfering in many components of this system such as macrophages, lymphocytes and neutrophils [9]. n-Hexadecanoic acid possess nematicide, pesticide, anti-androgenic, flavor, hemolytic 5-alpha reductase inhibitor, antioxidant and hypo-cholesterolemic properties as reported by Komansilan, et al. [10]. Also, 9,12-octadecadienoic acid had been reported researchers to possess anti-inflammatory, nematicide, cancer preventive, hypocholesterolemic and hepatoprotective activities [11]. There was no observable microbial growth on the oil after exposure to the environment for six months. This could be suggested that the seed oil contains compounds that inhibit the growth

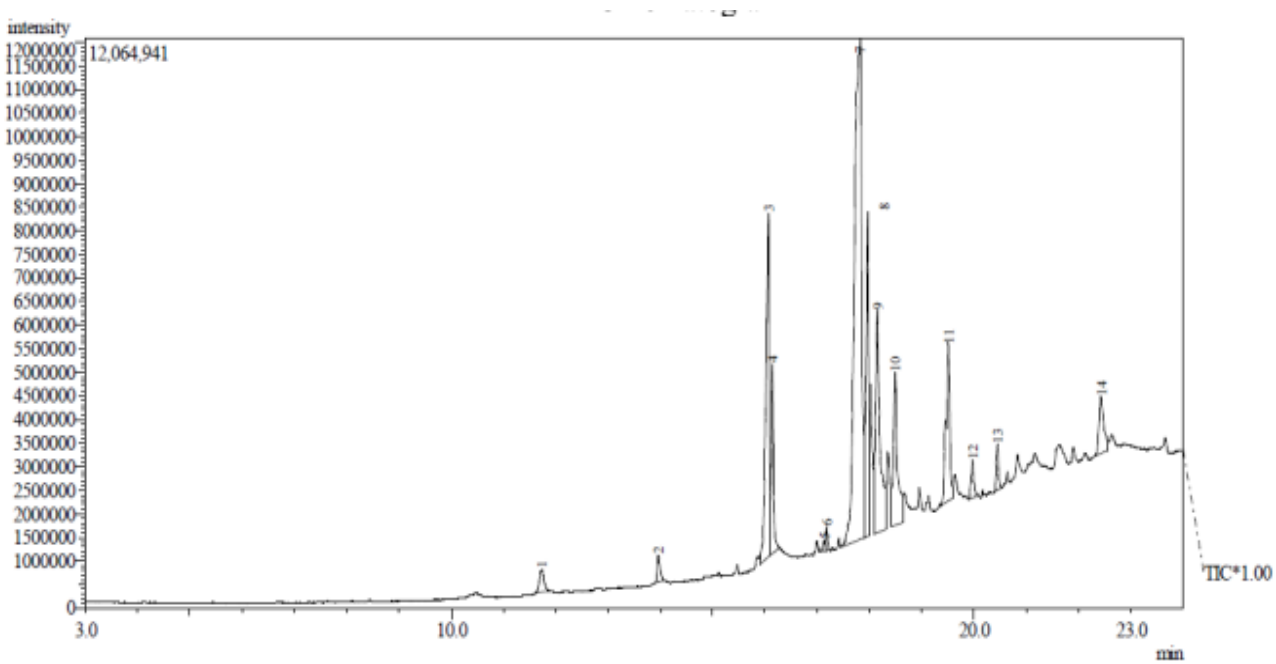

Figure 1: Chromatogram of avocado seed oil fatty acid profile. 
Citation: Omeje KO, Ozioko JN, Opmeje HC (2018) Pharmacological Potentials, Characterization and Fatty Acids Profile of Persea americana Mill. (Avocardo) Seed Oil Using Gas Chromatography-Mass Spectroscopy. Biochem Anal Biochem 7: 361. doi: 10.4172/2161-1009.1000361

Page 3 of 3

\begin{tabular}{|c|c|c|c|c|c|}
\hline Peaks & R. Time & MW & Area $\%$ & Name & Formulae \\
\hline 1 & 11.73 & 200 & 1.05 & Dodecanoic acid & $\mathrm{C}_{12} \mathrm{H}_{24} \mathrm{O}_{2}$ \\
\hline 2 & 13.96 & 228 & 0.86 & Tetradecanoic acid & $\mathrm{C}_{14} \mathrm{H}_{28} \mathrm{O}_{2}$ \\
\hline 3 & 16.06 & 256 & 13.19 & n-Hexadecanoic acid & $\mathrm{C}_{16} \mathrm{H}_{32} \mathrm{O}_{2}$ \\
\hline 4 & 16.14 & 284 & 4.12 & Hexadecanoic acid & $\mathrm{C}_{18} \mathrm{H}_{36} \mathrm{O}_{2}$ \\
\hline 5 & 17.13 & 294 & 0.28 & 9,12-Octadecanoic acid & $\mathrm{C}_{19} \mathrm{H}_{34} \mathrm{O}_{2}$ \\
\hline 6 & 17.18 & 296 & 0.45 & 11-Octadecanoic acid & $\mathrm{C}_{19} \mathrm{H}_{36} \mathrm{O}_{2}$ \\
\hline 7 & 17.82 & 282 & 40.33 & Oleic acid & $\mathrm{C}_{18} \mathrm{H}_{34} \mathrm{O}_{2}$ \\
\hline 8 & 17.96 & 284 & 9.69 & n-Hexadecanoic acid & $\mathrm{C}_{18} \mathrm{H}_{36} \mathrm{O}_{2}$ \\
\hline 9 & 18.15 & 248 & 11.45 & 1,E-11-Z-13-octadecatriene & $\mathrm{C}_{18} \mathrm{H}_{32}$ \\
\hline 10 & 18.48 & 248 & 6.78 & 1,E-11-Z-13-octadecatriene & $\mathrm{C}_{18} \mathrm{H}_{32}$ \\
\hline 11 & 19.51 & 184 & 6.31 & Undecylanic acid & $\mathrm{C}_{11} \mathrm{H}_{20} \mathrm{O}_{2}$ \\
\hline 12 & 19.96 & 308 & 1.14 & Palmitaldehyde, Diisopentylacetal & $\mathrm{C}_{16} \mathrm{H}_{54} \mathrm{O}_{2}$ \\
\hline 13 & 20.44 & 266 & 1.18 & 9-Octadecanal & $\mathrm{C}_{18} \mathrm{H}_{34} \mathrm{O}$ \\
\hline 14 & 22.42 & 338 & 3.17 & (E)-13-Docosenoic acid & $\mathrm{C}_{22} \mathrm{H}_{42} \mathrm{O}_{2}$ \\
\hline
\end{tabular}

Table 2: Properties of the fatty acids profile of avocado seed oil.
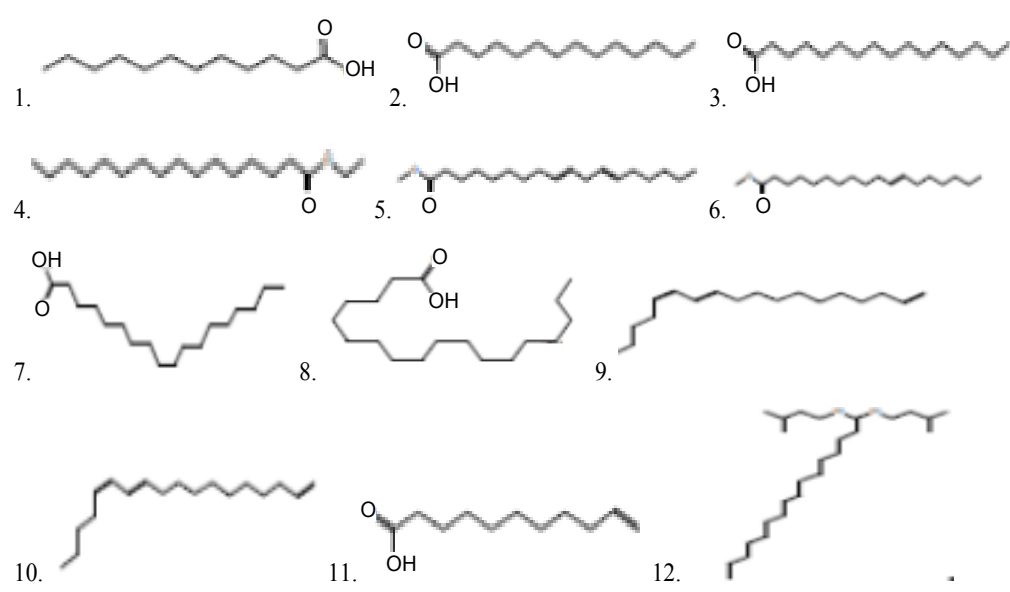

13

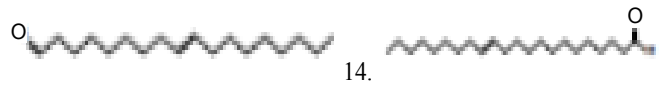

Figure 2: Chemical structures of the detected fatty acids.

of microbes. Undecylenic acid had been reported to be antifungal, as it is used in the treatment of skin fungal infection such as athletics' foot itching (Wikipedia, 2018).

\section{References}

1. Yasir M, Das S, Kharya MD (2010) The phytochemical and pharmacological profile of Persea americana Mill. Pharmacogn Rev 4: 77-84.

2. Daurte PF, Chaves MA, Borges CD, Mendonca CRB (2016) Avocado: characteristics, health benefits and uses. Ciencia Rural 46: 747-754.

3. Hamm W, Hamilton RJ, Calliauw G (2013) Edible oil processing (2ndedn), John Wiley \& Sons, Ltd 1-10.

4. Adebayo SE, Orhevba BA, Adeoye PA, Musa JJ, Fase OJ (2012) Solven extraction and characterization of oil from African star apple seed. Acad Res Int 3: 178-183.

5. Ononogbu IC (2002) Lipids in Human Existence. AP Express publishers, Nsukka, Nigeria 2-9.
6. Kyari MZ (2008) Extraction and characterization of seed oils. Int Agrophysics 22: $139-142$.

7. Adepoju TF, Olawale O, Okunola AA, Olatunji EM (2014) Solvent extraction of oil from sours of oilseeds and its quality characterization. Int J Sustain Energy Environ Res 3: 80-89.

8. Okereke SC, Arunsi UO, Nosiri Cl (2017) GC-MS/FT-IR screening of Xylopia aethiopica (Dunal) A. Rich fruit. Afr J Biochem Res 11: 12-17.

9. Sales-Campos H, Souza PR, Peghini BC, da Silva JS, Cardoso CR (2013) An overview of the modulatory effects of oleic acid in health and disease. Mini Rev Med Chem 13: 201-210.

10. Komansilan A, Abadi AL, Yanuwiadi B, Kaligis DA (2012) Isolation and identification of biolarvicide from Soursop (Annona muricata Linn) seeds to mosquito (Aedes aegypti) larvae. Int J Eng Technol 12: 28-32.

11. Sermakkani M. Thangapandian V (2012) GC-MS analysis of Cassia italica leaf methanol extract. Asian J Pharm Clin Res 5: 90-94. 